\title{
Urgences
}

\section{Poules et coqs}

\section{Alain St-Yves}

Numéro 12, 3e trimestre 1984

\section{Spécial humour}

URI : https://id.erudit.org/iderudit/025184ar

DOI : https://doi.org/10.7202/025184ar

Aller au sommaire du numéro

\section{Éditeur(s)}

Urgences

\section{ISSN}

0226-9554 (imprimé)

1927-3924 (numérique)

Découvrir la revue

\section{Citer ce document}

St-Yves, A. (1984). Poules et coqs. Urgences, (12), 41-46.

https://doi.org/10.7202/025184ar d'utilisation que vous pouvez consulter en ligne.

https://apropos.erudit.org/fr/usagers/politique-dutilisation/ 


\section{ALAIN ST-YVES}

\section{Poules et coqs}

Ces écritures volatiles et emplumées sont dédiées au poulet Hubert, saint patron de toutes les volailles. 


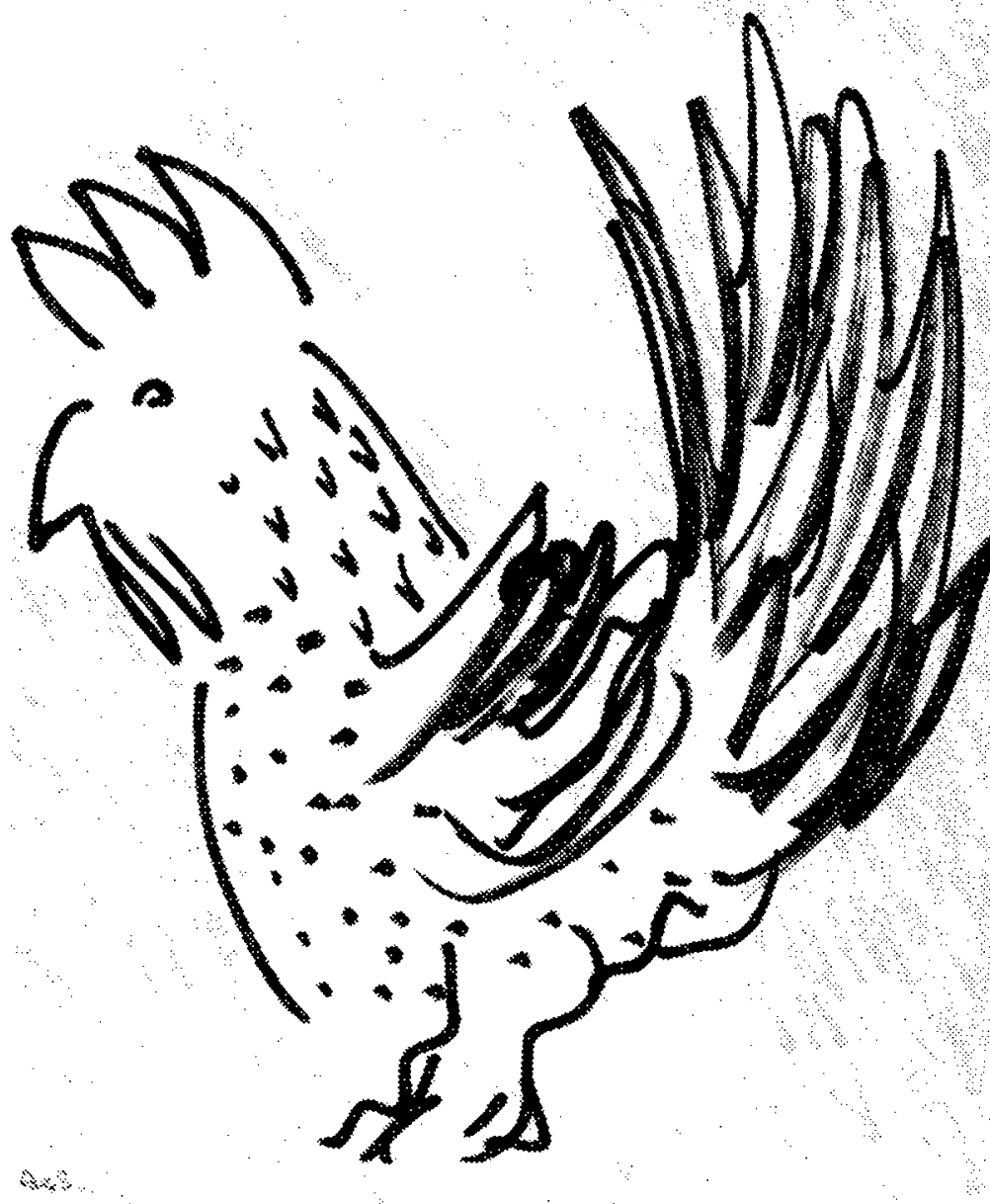




\section{Poulets et coqs}

La maison des poules: un poulailler celle des coqs: une bicoq

$*$

Des coquetiers ivres dirent à un jeune coq qui passait par là "arrête de faire ton coq!"

Celui-ci pour leur faire plaisir fit son jars de cane Cette démonstration coquine ne leur plut guère Alors nos marchands de volailles rouges comme des cogs crièrent "si tu continues à faire le coq on te coupe le cou" Le pauvre oiseau tout en sueur apeuré par ces grosses voix menaçantes

fit la poule mouillée

ce qui déplut davantage aux alcooliques grossistes

Le coquelet dans un dernier effort pour satisfaire les caprices des pochards volailleurs trouva prématurément la mort en essayant de se transformer en coq au vin

*

Poule qui roule n'amasse pas mousse

*

Un vieux coq qui avait beaucoup péché pour être pardonné et pouvoir ainsi gagner son ciel devint coq de clocher d'église

*

Le coq Pit est maître-chantre en la chapelle des aurores

*

Le regroupement féministe des poules du poulailler à Sylvie juchées sur des piquets de grève 
ont manifesté leur indignation et demandé

que les termes "oeuf à la coq" soient changés pour "oeuf à la poule"

*

Le coq à l'âne: "pour une fois change pas d'sujet!"

*

Le coq à la voix de rossignol

qui voulait obstinément devenir chanteur de rock and roll

a presque réussi

Il fut longtemps le coq d'Elvis

*

Les snobs pensent en cul-de-poule

*

Quelques poules coquettes vont prendre un ver au bar Becue et faire du bec aux coquins Parfois quand la séduction opère elles réussissent à se payer des coqtails

*

Un coq macho fréquentant le même bar se fait une fierté de ne se tenir qu'avec des poules de luxe

Dans un coin du poulailler à Nicky se tenait un coq mélancolique qui semblait toujours avoir une grosse poule dans la gorge *

Le soleil commençait à peine à poindre quand un coq plus 
matinal que les autres monta sur la plus haute pierre de la plus haute tour pour chanter sa joie de revoir la lumière. Des ouvriers de l'équipe de nuit s'affairaient encore pour achever le travail fixé et ainsi respecter le calendrier des travaux. Juché au faîte de cet édifice inachevé, le coq regarda autour de lui pour s'assurer du matin qui pointait. II respira par trois fois, se déroua nerveusement puis, d'un seul trait vif et sonore, lança son chant matutinal.

Un homme qui travaillait à l'érection de la tour, pour se moquer, essaya d'imiter le chant du coq: kokadududu! Un ouvrier qui se trouvait près de lui le reprit en lui disant que le coq avait plutôt chanté "Kokékokko". Un troisième travailleur, sur ces entrefaites, intervint pour leur signaler qu'ils faisaient tous les deux erreur et que le coq avait dit dans son chant "cocorico". Mais non! Mais non! dit un quatrième, j'ai bien entendu "cocka-doddle-do". Et moi "kukuruku", d'ajouter une cinquième personne qui se trouvait là.

C'est alors que tous ceux qui travaillaient à l'édification de la tour - ils étaient fort nombreux - se mirent à élever la voix, à se chicaner, à se traiter de menteur et même de canaille.

- Ce maudit coq a chanté "quiquiriquiqui".

- C'est complètement faux! Je suis sûr et certain que c'était "coqueliki".

- Sales menteurs! Cette volaille chantait "kikikikou".

- Vous êtes vraiment tous sourds comme des pots. J'étais, moi, très près de cet oiseau de malheur et je vous jure que j'ai bien entendu "kutkutkut-kikoutte".

- Bande d'abrutis. Depuis ma tendre enfance je vis avec des coqs et ces tas de plumes ont toujours craché "kokoriki".

- "Croucroudidou" que j'vous dis. Je suis bien placé pour le savoir; je suis né dans une basse-cour! 
Et ainsi de suite. Tout le monde s'engueulait. Ce qui devait arriver, arriva. Ils en vinrent aux coups hauts et même aux coups bas. La violence prit une ampleur telle que rien ni personne ne put l'arrêter. Les pierres volèrent en éclats. Les murs se fendirent de toutes parts. Rapidement, la tour prit des allures infernales.

Le coq, devant ce sinistre tableau, s'éclipsa en douce, étonné que son chant ait provoqué une telle hécatombe et la destruction aussi rapide d'un édifice qui aurait à coup sûr fait la gloire et la fierté de la grande cité de Babel.

Le soleil était déjà bien haut quand le calme revint enfin. Mais la tour et le coq avait tout deux disparu.

*

Un coq amoureux à sa poulette: “j'adore tes pousseins”.

*

Un vieux coq prénommé Mayol

né à la Belle Epoque

aime bien à tous les matins

réveiller la ménagerie

en coquetant et en chantant "viens poupoule viens poupoule viens..."

La grande fofolle du navire: la coq

Les dentistes souhaitent la venue du jour où les poules auront des dents

Une vieille poulette grise seule dans sa remise chantonne et tricote-cote-cote-cote... 
Expérience amusante à tenter en temps de Pâques seulement Prenez tous vos oeufs en chocolat et mettez-les à couver peridant un certain temps Ensuite prenez patience et attendez peut-être écloront-ils

Si oui ça vous fera plein de belles petites poules en chocolat

N.B.: Si l'expérience réussit

nourrissez vos poussins avec du cacao

*

On a dû tuer un coq obsédé sexuel

II avait des envols maladifs

et n'en finissait pas d'avoir la chair de poule

*

Le plus révolutionnaire de la basse-cour: le coq tel Molotov

*

De grosses poules bien installées sur leur nid douillet caquettent en regardant passer

une coquette jeune poulette au plumage roux

au bras d'un vieux coquelucheux à la crête douteuse

*

Que celui ou celle qui n'a jamais péché en faisant ce genre de blague facile avec les mots me lance le premier oeuf

Ô écriveux qui a scribouillé tous ces textes parfois si ridicules attention aux Oeufs Volants Non Identifiés! 


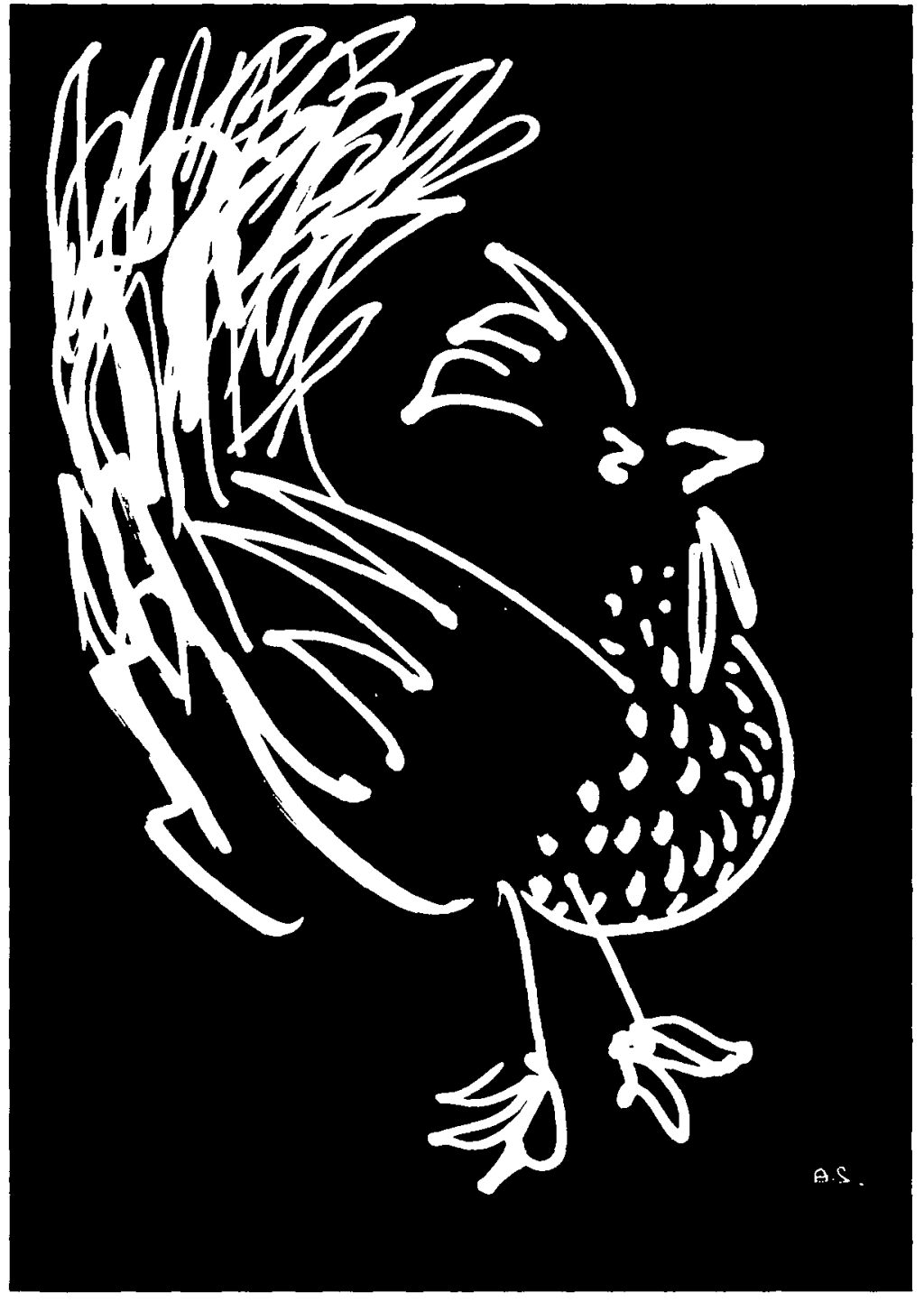

